\title{
CARACTERIZAÇÃO PÓS-COLHEITA E SENSORIAL DE GENÓTIPOS DE BANANEIRAS TIPO PRATA ${ }^{1}$
}

\author{
ARIANE CASTRICINI ${ }^{2}$, LEANDRA OLIVEIRA SANTOS ${ }^{3}$, ROSIRES DELIZA ${ }^{4}$, \\ EUGÊNIO FERREIRA COELHO ${ }^{5}$, MARIA GERALDA VILELA RODRIGUES ${ }^{2}$
}

RESUMO- O norte de Minas Gerais é grande produtor de banana 'Prata-Anã' irrigada, cultura altamente suscetível ao Mal-do-Panamá. O uso de genótipos resistentes é uma alternativa, mas os frutos devem apresentar características pós-colheita o mais próximo possível da 'Prata-Anã', para melhor aceitação pelos consumidores. O objetivo do trabalho foi caracterizar frutos em pós-colheita, identificar a preferência e a intenção de compra de diferentes genótipos de bananeira tipo Prata. Os genótipos Prata-Anã, BRS Platina e Fhia-18. foram caracterizados no ponto de colheita (verdes) e maduros (estádio seis de maturação), por avaliações químicas, físicas e sensoriais. Quando verde, 'BRS Platina' apresentou maior massa fresca e tamanho que 'Fhia-18' e 'Prata-Anã'. 'Fhia-18.' teve a tonalidade verde da casca mais intensa que a dos demais genótipos. Madura, 'BRS Platina' foi mais firme, mas com a mesma resistência ao despencamento que 'Fhia-18' e superior à 'Prata-Anã'. 'Fhia-18' apresentou cor da casca com amarelo mais clara e tão brilhante quanto da 'Prata-Anã', mas 'BRS Platina' teve a tonalidade de amarelo mais intensa. Bananas 'Fhia-18' foram mais ácidas, 'BRS Platina', com menor acidez titulável, e 'Prata-Anã', o maior teor de sólidos solúveis. Os genótipos Prata-Anã e BRS Platina tiveram maior preferência e intenção de compra pelos consumidores, sendo as bananas 'Prata-Anã' em dedos e 'BRS Platina' e 'Fhia-18' em dedos, buquê e penca, as mais preferidas. Entretanto, a maioria compraria bananas 'Prata-Anã' em buquê e 'BRS Platina' e 'Fhia-18' em penca. Enquanto verdes, os genótipos foram semelhantes à 'Prata-Anã', e maiores diferenças químicas e físicas ocorreram quando maduros.

Termos para Indexação: Musa sp., avaliação química e física, aparência, consumidor.

\section{POSTHARVEST AND SENSORY CHARACTERIZATION OF BANANA GENOTYPES TYPE PRATA}

\begin{abstract}
The north of Minas Gerais is a major producer of irrigated 'Prata Anã' banana, which is highly susceptible to fusarium wilt. The use of resistant genotypes is an alternative, but the fruits have to present characteristics similar to the 'Prata Anã', to achieve better consumer acceptance. This study aimed at characterizing fruits in postharvest, and identifying consumer preference and intention to purchase 'Prata' banana genotypes. The banana genotypes: 'Prata Anã', 'BRS Platina' and 'Fhia-18' were characterized at the point of harvest (green) and when ripe (stage six of maturity), through chemical, physical and sensory evaluations. When green, the 'BRS Platina' had higher fresh weight and size than 'Fhia-18' and 'Prata Anã'. Fruits of 'Fhia-18' had the green color of the skin more intense than 'Prata Anã' and 'BRS Platina'. When ripe, 'BRS Platina' was firmer, but with the same dropping resistance of 'Fhia-18' and higher than 'Prata Anã'. 'Fhia-18' presented the yellow skin color lighter than 'Prata Anã but as bright as the latter, and 'BRS Platina' had a stronger yellow skin. Bananas 'Fhia-18' had a higher titrable acidity, 'Prata Anã' had the highest soluble solids. The genotypes 'Prata Anã' and 'BRS Platina' were preferred and had a higher consumer intention to purchase. Participants in the study preferred 'Prata Anã' banana in fingers, and 'BRS Platina' and 'Fhia-18' in fingers, bouquet, and bunch. However, the majority of consumers stated that they would buy 'Prata Anã' banana in bouquet and 'BRS Platina' and 'Fhia-18' in bunch. When green the genotypes were similar to 'Prata Anã', and higher chemical and physical differences occurred when they were ripened. Index terms: Musa sp, chemical and physical evaluation, appearance, consumer.
\end{abstract}

${ }^{1}$ (Trabalho 058-14). Recebido em: 13-02-2014. Aceito para publicação em: 01-07-2014.

${ }^{2}$ Eng a Agrônoma, Dra., Pesquisadora, Epamig Norte de Minas, FEGR, Bolsista Fapemig, Nova Porteirinha - MG. E-mail: ariane@, epamig.br; magevr@epamig.br

${ }^{3}$ Eng $^{a}$ Agrônoma, Dra., Bolsista de Pós-Doutorado CNPq, Epamig Norte de Minas, FEGR, Nova Porteirinha - MG. E-mail: leandraoli@yahoo.com.br

${ }^{4}$ Eng $^{\mathrm{a}}$ de Alimentos, PhD., Pesquisadora Embrapa Agroindústria de Alimentos, Rio de Janeiro -RJ. E-mail: rosires.deliza@embrapa.br ${ }^{5}$ Eng $^{\mathrm{o}}$ Agrícola, Dr., Pesquisador Embrapa Mandioca e Fruticultura Tropical, Cruz das Almas - BA. E-mail;eugenio@cnpmf.embrapa.br 


\section{INTRODUÇÃO}

A fruticultura irrigada proporciona emprego e renda em regiões caracterizadas pela pobreza e seca, como o semiárido mineiro que, atualmente, é o segundo maior produtor de frutas do Estado. A região gera cerca de 50 mil empregos diretos, seja por grandes empresas, seja por pequenos produtores, o valor da produção de frutas em 2012 foi estimado em R \$ 512 milhões (IBRAF, 2013).

O norte de Minas Gerais, semiárido, é o terceiro maior polo produtor de banana do País, com produção de 322,4 mil toneladas em 14,1 mil hectares (IBGE, 2013).

A principal doença que hoje dificulta e, até mesmo, impede o cultivo da 'Prata-Anã' em algumas propriedades da região é o mal-dopanamá. Esta doença não possui controle químico e, segundo Nomura et al. (2013), uma das estratégias para solucionar a falta de cultivar "adequada" é a criação de novos genótipos resistentes a doenças e pragas, que apresentem porte baixo, que sejam altamente produtivos e sabor semelhante às cultivares tradicionalmente aceitas pelo consumidor. Este genótipo, entretanto, precisa ser o mais próximo possível da 'Prata-Anã', para que possa atender ao mercado consumidor hoje trabalhado pelos produtores da região norte de Minas Gerais. 'BRS Platina' e 'Fhia-18' são híbridos tetraploides (AAAB), que tiveram como parental feminina a 'Prata-Anã' (AAB). Estes genótipos apresentam ótimo desempenho agronômico, já constatado em vários trabalhos desenvolvidos na região norte de Minas Gerais, porém somente poderão ser cultivados em larga escala, se forem aceitos pelo consumidor. De acordo com Donato et al. (2006), a 'Prata-Anã' é um mutante de 'Branca', porte baixo a médio, de baixa produtividade, suscetível às sigatokas-amarela e negra e ao mal-do-panamá. A 'BRS Platina' (AAAB) é um híbrido tipo Prata (Prata-Anã x M53), porte baixo a médio, resistente às sigatokas-amarela e negra e ao mal-do-panamá (DONATO et al., 2006; CORDEIRO et al., 2006). A bananeira 'Fhia-18' é um híbrido tetraploide (AAAB) de 'Prata-Anã' (subgrupo Prata), que se tem mostrado resistente à sigatoka-negra, moderadamente suscetível à sigatoka-amarela e tolerante ao mal-do-panamá (COSTA et al., 2012).

Os frutos de bananeira são colhidos em estádio verde, porém fisiologicamente desenvolvidos e, por serem climatéricos, completam seu amadurecimento após a colheita. A caracterização dos frutos neste ponto de colheita permite identificar diferenças relativas de cada genótipo, possibilitando obter informações que possam nortear a colheita, o transporte interno, as embalagens, o transporte externo, com base na suscetibilidade a danos mecânicos, facilidade de despencamento, tamanho dos frutos, coloração, forma de apresentação e sabor, direcionando-os de acordo com as exigências do mercado. A comercialização final, feita pelos varejistas, geralmente se dá com frutos nos estádios 5 e 6 da escala de Loesecke, a qual, apesar de antiga, continua sendo utilizada (SILVA et al., 2013). Os consumidores estão habituados a comprar bananas em pencas ou em buquês, porém pouco se sabe sobre sua aceitação e interesse pela apresentação em dedos individuais. A aparência dos frutos, caracterizada pelo tamanho, diâmetro, massa, firmeza, resistência ao despencamento e cor, tem importante papel na escolha e na decisão de compra do consumidor. A identificação dos genótipos mais adequados, assim como a forma de apresentação que seja aceita pelos consumidores, será fundamental no direcionamento do trabalho dos melhoristas da 'Prata-Anã'. O objetivo do trabalho foi caracterizar frutos em póscolheita e identificar a preferência e a intenção de compra de diferentes genótipos de bananeira tipo Prata.

\section{MATERIAL E MÉTODOS}

Os frutos foram produzidos na Fazenda Experimental do Gorutuba (FEGR), pertencente à Epamig, localizada no perímetro irrigado do Gorutuba, município de Nova Porteirinha - MG, na latitude de $15^{\circ} 47^{\prime} 29^{\prime \prime} \mathrm{S}$, longitude de $43^{\circ} 17^{\prime} 88^{\prime \prime}$ $\mathrm{W}$, com altitude média de $500 \mathrm{~m}$, precipitação pluvial média anual de $800 \mathrm{~mm}$, e o clima, baseado na classificação internacional de Köppen, do tipo Aw (tropical de savana) (ANTUNES, 1986). O clima local é monitorado pela estação meteorológica do INMET, localizada no mesmo município do estudo.

Os cultivos foram originados de mudas provenientes da cultura de tecidos, em espaçamento de 2,0 x 2,5 m. O solo foi preparado com aração, gradagem e sulcamento, e a correção química, feita de acordo com as necessidades, a partir da análise de solo. Tanto a adubação quanto as demais práticas culturais (desbaste, desfolha, controle de plantas infestantes, monitoramento e manejo da brocado-rizoma e do Trips-da-Erupção - únicas pragas presentes) foram realizadas conforme recomendações para o manejo da 'Prata-Anã' cultivada na região, resumidas em Rodrigues et al. (2008).

O sistema de irrigação utilizado foi o de microaspersão, com um emissor para cada quatro plantas, com intensidade de aplicação média de 
2,54 $\mathrm{mm} \mathrm{h}^{-1}$. A lâmina de irrigação foi calculada em função da evapotranspiração da cultura (ETc) da bananeira, obtida da evaporação do tanque classe A e do coeficiente do tanque, que resultaram na evapotranspiração máxima de referência. O produto da evapotranspiração máxima pelo coeficiente de cultura, recomendado por Allen et al. (1998), resultou na evapotranspiração da cultura.

Os genótipos utilizados neste estudo foram: Prata-Anã, BRS Platina e Fhia-18, constituindo os três tratamentos do estudo. A colheita foi feita quando os frutos atingiram o ponto de maturidade comercial: frutos com máximo crescimento, ainda ligeiramente quinados, e com casca totalmente verde, ou seja, no estádio dois da escala de Loesecke (1950), que apesar de antiga continua sendo a referência utilizada. Após a colheita, os frutos foram encaminhados ao Laboratório de Pós-Colheita da FEGR e caracterizados enquanto verdes e quando maduros. Consideraram-se frutos maduros aqueles no estádio seis de maturação, de acordo com a mesma escala. Os mesmos permaneceram no laboratório em temperatura ambiente $\left(25 \pm 2^{\circ} \mathrm{C}\right)$, por aproximadamente uma semana, até a maturação.

Para diminuir o efeito das variações naturalmente existentes entre frutos de diferentes pencas, foram utilizados frutos da segunda e da terceira pencas, para avaliações dos frutos verdes e quando maduros, respectivamente. Foi aplicado o delineamento inteiramente casualizado, com três repetições de cinco frutos por parcela e análise de variância entre genótipos. As diferenças entre as médias foram checadas pelo teste de Tukey, a 5\%, utilizando-se do software Saeg 9.1 (2007).

As avaliações comuns para ambos os estádios de maturação foram: 1- massa fresca $(\mathrm{g})$ obtida por pesagem em balança digital; 2- comprimento $(\mathrm{cm})$ medido com fita métrica na curvatura externa do fruto, entre a inserção do pedúnculo e a extremidade oposta; 3-diâmetro (mm) obtido com paquímetro digital, na região mediana dos frutos; 4- firmeza da polpa $(\mathrm{N})$ determinada na região equatorial dos frutos com casca, medida com penetrômetro digital; 5- coloração da casca determinada através do Colorímetro Minolta, modelo Chroma meter CR 400, sistema L C H. O colorímetro expressa a cor, utilizando três parâmetros: (a) luminosidade (L*), que varia entre 0 (preto) e 100 (branco); (b) cromaticidade ou pureza da cor $\left(\mathrm{C}^{*}\right)$, cujos valores relativamente inferiores representam cores impuras (acinzentadas), e os superiores, as cores puras, e (c) ângulo de tonalidade ou cor verdadeira ( ${ }^{\circ} \mathrm{Hue}$ ), que varia entre $0^{\circ}$ e $360^{\circ}$, sendo que o ângulo $0^{\circ}$ corresponde à cor vermelha, $90^{\circ}$ à cor amarela, $180^{\circ}$ ou $-90^{\circ}$ à cor verde, $270^{\circ} \mathrm{ou}-180^{\circ}$ à cor azul, e passa de vermelho a negro em $360^{\circ}$ (MORAIS et al., 2002). As avaliações de resistência ao despencamento (PIMENTEL et al., 2010), pH, sólidos solúveis ( ${ }^{\circ}$ Brix) e da acidez titulável (\%) (INSTITUTO ADOLFO LUTZ, 1987) da polpa foram feitas somente nos frutos maduros (estádio 6).

A avaliação da preferência quanto à aparência dos genótipos, nas distintas formas de apresentação (dedo, buquê e penca), foi realizada aleatoriamente, com 43 consumidores de bananas. Os testes foram realizados nas dependências do Laboratório de Pós-Colheita da Unimontes, Câmpus de Janaúba. A ordem de apresentação foi balanceada, seguindo o delineamento de blocos completos, sendo utilizada a escala hedônica estruturada de nove pontos, variando de 1: "desgostei extremamente" a 9: "gostei extremamente" (STONE; SIDEL, 1995; MEILGARD et al., 1988). Os frutos de cada genótipo avaliados em penca (10 frutos), em dedos (cinco frutos destacados da almofada) e em buquê (cinco frutos não destacados da almofada) foram apresentados em bandejas individuais, codificadas com números de três dígitos. Para o estudo de preferência entre os genótipos, os frutos foram apresentados em penca, contendo dez dedos.

Os dados referentes à preferência pelos genótipos foram submetidos à análise de variância (ANOVA) e teste de Tukey, considerando genótipos e formas de apresentação como causas de variação. Os dados de preferência, em função das formas de apresentação dos diferentes genótipos, foram analisados pela ferramenta Mapa Interno da Preferência - MIP (GREENHOFF; MacFIE, 1994), utilizando-se do software XLSTAT. A intenção de compra também foi avaliada, utilizando-se das opções "compraria" ou "não compraria", tanto para os diferentes genótipos quanto para a forma de apresentação dos mesmos. As respostas foram tabuladas e são apresentadas em termos de porcentagem.

\section{RESULTADOS E DISCUSSÃO}

Frutos no ponto de colheita (verdes) - $\mathrm{Na}$ Tabela 1, estão os resultados da análise de variância para frutos no ponto de colheita, indicando diferença significativa para massa fresca, comprimento, diâmetro e ângulo hue da casca entre bananas 'PrataAnã', 'BRS-Platina' e 'Fhia-18'. A firmeza da polpa e os parâmetros de cor da casca $L$ e $C$ não foram diferentes entre os diferentes genótipos.

Bananas 'BRS Platina' tiveram massa fresca superior à 'Prata-anã' e 'Fhia-18', e entre os três 
genótipos, a 'Prata-Anã' tem frutos mais leves (Tabela 2), corroborando os resultados obtidos por Donato et al. (2006), que também verificaram que bananas 'Prata-Anã' apresentaram massa fresca inferior à de 'BRS Platina', em dois ciclos de produção. De acordo com os mesmos autores, a massa do fruto é um caráter importante para os trabalhos de melhoramento, sendo que não pode ser considerada isoladamente, mas, sim, associada a outros componentes que refletem a qualidade dos frutos, como o comprimento e o diâmetro. Silva et al. (2002) afirmaram que a massa média dos frutos em híbridos é sempre superior ao genitor, neste caso 'Prata-Anã'. A média para o comprimento e o diâmetro dos frutos está apresentada na Tabela 2. Apesar de os frutos terem massa fresca diferente, o comprimento foi semelhante, ou seja, bananas 'PrataAnã' não diferiram estatisticamente de 'Fhia-18', que por sua vez teve o mesmo comprimento de 'BRS Platina'. Entretanto, 'Prata-Anã' apresentou menor comprimento que 'BRS Platina'. De acordo com as normas de classificação da CEAGESP (2006), a classe da banana é determinada pelo comprimento do fruto. Neste sentido, as bananas 'Prata-Anã' deste trabalho estão dentro da classe 18 (que compreende frutos maiores que $18 \mathrm{~cm}$ até $22 \mathrm{~cm}$ ), e as bananas 'BRS Platina' e 'Fhia-18', dentro da classe 22 (maior que $22 \mathrm{~cm}$ até $26 \mathrm{~cm}$ ).

Não houve diferença estatística entre o diâmetro de 'Prata-Anã' e 'Fhia-18', sendo essas estatisticamente inferiores à 'BRS Platina', que apresentou frutos com maior diâmetro (Tabela 2). Apesar da diferença de diâmetro, os três genótipos estão classificados dentro da categoria extra (CEAGESP, 2006), que exige diâmetro mínimo de $34 \mathrm{~mm}$.

Os frutos dos diferentes genótipos não diferiram quanto à firmeza da polpa, luminosidade e cromaticidade da casca.

A intensidade da cor verde da casca pode ser vista na Tabela 2, através dos valores de ${ }^{\circ}$ hue. Bananas 'Fhia-18' apresentaram a tonalidade da casca verde mais intensa que a 'Prata-Anã' e 'BRS Platina', sendo que estas últimas não diferiram em relação à tonalidade de verde da casca.

\section{Frutos maduros (estádio 6 de coloração} da casca) - de acordo com os resultados da análise de variância, houve diferença significativa entre os genótipos para todas as variáveis químicas e físicas avaliadas, exceto para o diâmetro (Tabela 3). Os valores de massa fresca de bananas maduras 'PrataAnã', 'BRS Platina' e 'Fhia-18' estão apresentados na Tabela 4. Frutos de 'Prata-Anã' tiveram menor massa fresca que os demais genótipos, os quais não diferiram estatisticamente entre si. Em três ciclos de produção, bananas 'BRS Platina' tiveram maior massa quando comparadas à 'Prata-Anã', de acordo com Oliveira et al. (2008). De acordo com Silva et al. (2006), a perda de massa é acentuada quanto maior o grau de amadurecimento da fruta, chegando a níveis demasiados na senescência, quando esta não se apresenta mais apta à comercialização.

Foi observada redução da massa fresca em 'Prata-Anã' (6,69\%) e 'BRS Platina' (18,30\%) nos frutos maduros (Tabela 4), quando comparada aos frutos no ponto de colheita (Tabela 2). Menor perda de massa durante o amadurecimento é uma característica a ser considerada na escolha do genótipo, pois de acordo com Santos et al. (2006), tais perdas podem refletir sobremaneira no aspecto comercial da banana, pois sua comercialização, geralmente, dá-se por meio de sua massa.

O diâmetro dos frutos maduros não diferiu estatisticamente, sendo os valores médios de 38,41 $\mathrm{mm}, 39,42 \mathrm{~mm}$ e $39,37 \mathrm{~mm}$ para bananas 'PrataAnã', 'BRS Platina' e 'Fhia-18', respectivamente (Tabela 4). Jesus et al. (2004) verificaram que bananas 'Prata-Anã' tiveram o mesmo tamanho e menor diâmetro que 'Galil-18'. De acordo com as Normas de Classificação da CEAGESP (2006), os frutos enquadraram-se na categoria extra, que compreende frutos do grupo Prata com calibre de $34 \mathrm{~mm}$ ou maior. Quanto ao comprimento, bananas 'Prata-Anã' foram menores que 'BRS Platina' e 'Fhia-18', e de acordo com a CEAGESP (2006), os frutos de 'Prata-Anã' são agrupados na classe 18, e os demais, na classe 22. O agrupamento em classes garante a homogeneidade de tamanho entre frutos do mesmo lote. Oliveira et al. (2010b) verificaram que bananas 'Prata-Anã' maduras tiveram menor comprimento e diâmetro que a 'BRS Platina'.

Bananas 'BRS Platina' apresentaram polpa mais firme que a da 'Fhia-18' e estatisticamente foi igual à da 'Prata-Anã' (Tabela 4). Oliveira et al. (2010a) e Pimentel et al. (2010) encontraram valores de firmeza da polpa de 'Prata-Anã' superiores aos da 'BRS Platina', durante o amadurecimento. Castricini et al. (2012) verificaram o efeito de diferentes lâminas de irrigação (25\% ETo, $50 \%$ ETo, $75 \%$ ETo, $100 \%$ ETo e $125 \%$ ETo) na firmeza de bananas e, em todas as lâminas, a firmeza de 'BRS Platina' foi estatisticamente igual à de 'Fhia-18', exceto a $125 \%$ ETo, em que bananas 'BRS Platina' tiveram polpa mais firme.

Os parâmetros de cor da casca estão apresentados na Tabela 4. Bananas 'BRS Platina' tiveram a tonalidade (ângulo hue) amarela da 
casca mais intensa que as demais; entretanto, os menores valores de croma (C) e luminosidade (L) indicam que a casca é menos brilhosa e mais escura que a da 'Prata-Anã' e da 'Fhia-18'. O ângulo hue expressa as diferenças na coloração da casca, permitindo visualizar a mudança na cor dos frutos, de verde para amarela (AZZOLINI et al., 2004). Tanto a degradação de clorofilas como a síntese de carotenoides são processos modulados pelo etileno durante o amadurecimento, mas a tonalidade da cor também pode ser uma característica genética, conferindo diferentes nuances à casca dos frutos.

Bananas 'BRS Platina' e 'Fhia-18' tiveram maior resistência ao despencamento que 'Prata-Anã', conforme apresentado na Tabela 4 . O despencamento ou queda natural de frutos é um dos maiores problemas de pós-colheita da banana, restringindo a comercialização. Este fenômeno é resultado do amolecimento e enfraquecimento fisiológico do pedicelo, que leva à separação individual dos frutos da penca com muita facilidade (NEW; MARRIOTT, 1983).

De acordo com os valores médios de despencamento dos frutos de bananeira obtidos pelo "Despencador Mecanizado" e com a experiência e os critérios práticos no Laboratório de Práticas Culturais da Embrapa Mandioca e Fruticultura, definiram-se os seguintes padrões de resistência ao despencamento: 1) Resistente $(>60 \mathrm{~N})$; 2) Medianamente Resistente (20-60 N), e 3) Suscetível $(<20$ N) (PEREIRA et al., 2004). De acordo com esta classificação, os três genótipos utilizados neste estudo ('Prata-Anã', 'BRS Platina' e 'Fhia-18') foram suscetíveis ao despencamento, visto que todos apresentaram resistência ao despencamento inferior a 10 N. Pimentel et al. (2010) verificaram que, no índice de cor da casca 6 (casca amarela), a 'BRS Platina' demonstrou ser suscetível ao despencamento, enquanto a 'Prata-Anã' foi medianamente resistente.

A acidez titulável da polpa de bananas 'Galil-18' foi maior que a dos demais genótipos analisados (Tabela 4); consequentemente, a polpa apresentou menor $\mathrm{pH}$. Jesus et al. (2004) relataram que a 'Fhia-18' possui a polpa menos ácida que a 'Prata-Anã'. 'BRS Platina' apresentou frutos menos ácidos, com valor de $\mathrm{pH}$ intermediário em relação à 'Prata-Anã' e 'Fhia-18'. Pimentel et al. (2010) também verificaram que a acidez da polpa de 'BRS Platina' foi inferior à da 'Prata-Anã', no estádio seis de maturação, mas o pH não foi diferente, ao contrário de Oliveira et al. (2010b), que não encontraram diferença significativa para a acidez titulável e pH da polpa de bananas 'Prata-Anã' e 'BRS Platina'.
O teor de sólidos solúveis do genótipo PrataAnã foi superior ao de 'BRS Platina' e 'Fhia-18' (Tabela 4). Esta característica parece indicar que 'Prata-Anã' tem frutos mais doces que os demais genótipos, já que também foi identificado por outros autores (JESUS et al., 2004; GOMES et al., 2007; OLIVEIRA et al., 2010b; SILVA et al., 2012). Pimentel et al. (2010) verificaram que 'BRS Platina' apresentou características de fruto com maturação mais adiantada que a de 'Prata-Anã', quando comparadas no mesmo índice de coloração da casca (maturação). De acordo com os autores, somente no índice 6 de coloração, os frutos apresentaram características semelhantes.

\section{Análise sensorial}

Preferência dos consumidores entre os genótipos - houve diferença significativa entre os genótipos (Tabela 5) para a preferência em relação à aparência dos frutos. A Figura 1 corresponde às notas médias dadas pelos consumidores que avaliaram os frutos. Observou-se que as bananas 'Prata-Anã' e 'BRS Platina' receberam as maiores notas, sendo preferidas em relação a aparência como moderadamente, quando comparadas à 'Fhia-18', as quais foram menos preferidas, pois receberam menores notas, correspondente na escala a 'gostei ligeiramente'.

Intenção de Compra - de acordo com a Figura 2, verificou-se que a maioria $(86,1 \%)$ dos consumidores compraria bananas 'Prata-Anã', e que $81,4 \%$ e $67,4 \%$ comprariam bananas 'BRS Platina' e 'Fhia-18', respectivamente. Do total das pessoas que participaram do estudo, $32,56 \%$ não comprariam bananas 'Fhia-18', que também alcançou a menor aceitação.

Preferência dos consumidores quanto à forma de apresentacão das bananas - A Figura 3 mostra o Mapa Interno da Preferência, apresentando a posição dos consumidores (Fig. 3a) e das nove amostras de bananas avaliadas neste estudo (Fig. 3b). As duas primeiras dimensões explicaram 46,96 da variância total (dimensão 1: 26,08\% e dimensão 2: $20,89 \%$ ). Considerando que cada consumidor é representado por um vetor, e a extremidade deste indica a direção da preferência de referido consumidor, podemos observar que a maioria dos participantes deste estudo está localizada nos quadrantes inferior e superior esquerdo do gráfico, possibilitando inferir que as bananas preferidas dos consumidores foram 'Prata-Anã', penca e buquê; seguida por 'Fhia-18', penca; 'BRS Platina', dedos e penca. Um número mais reduzido de consumidores apreciou a 'Fhia-18', dedos e buquê; 'BRS Platina', 
buquê; e 'Prata-Anã', dedos.

Intenção de Compra - Na Figura 4 A, B e C, observou-se a intenção de compra de bananas 'PrataAnã', 'BRS Platina' e 'Fhia-18', respectivamente, apresentadas em dedos, buquê ou penca. Para 'PrataAnã', a maioria dos consumidores (93,0\%) compraria a fruta em buquê e $53,5 \%$ não comprariam na forma de dedos, resultado que foi coincidente com o do teste de aceitação. A intenção de compra para 'BRS Platina' e 'Fhia-18' foi semelhante, pois a maioria dos consumidores $(72,1 \%$ e $74,4 \%$, respectivamente) compraria frutos em penca, sendo que a porcentagem dos que comprariam os frutos em dedos ou buquê foi maior em comparação àqueles que não comprariam.

TABELA 1 - Análise de variância para massa fresca, comprimento, diâmetro, firmeza e cor da casca (*L, *C e ${ }^{\circ}$ h) de 'Prata-Anã', 'BRS-Platina' e 'Fhia-18' no ponto de colheita.

\begin{tabular}{lcccccccc}
\hline \multicolumn{1}{c}{ FV } & GL & Massa fresca & Comprimento & Diâmetro & Firmeza & L & C & H \\
\hline Genótipos & 2 & $1865,4^{*}$ & $4,69^{*}$ & $30,91^{*}$ & $106,72^{\text {ns }}$ & $2,48^{\text {ns }}$ & $2,13^{\text {ns }}$ & $3,16^{*}$ \\
\hline Resíduo & 6 & 40,4 & 0,59 & 3,46 & 55,2 & 1,73 & 1,07 & 0,30 \\
CV (\%) & & 4,3 & 3,4 & 4,6 & 8,0 & 2,2 & 2,5 & 0,47 \\
\hline
\end{tabular}

*, ns $=$ significativo e não significativo a $5 \%$, respectivamente, pelo teste $\mathrm{F}$.

TABELA 2 - Caracterização pós-colheita de 'Prata-Anã', 'BRS Platina' e 'Fhia-18' no ponto de colheita.

\begin{tabular}{lccc}
\hline \multirow{2}{*}{ Características } & \multicolumn{3}{c}{ Genótipos } \\
\cline { 2 - 4 } & Prata-Anã & BRS Platina & Fhia-18 \\
\hline Massa Fresca $(\mathrm{g})$ & $127,17 \mathrm{C}$ & $176,17 \mathrm{~A}$ & $143,60 \mathrm{~B}$ \\
Comprimento $(\mathrm{cm})$ & $21 \mathrm{~B}$ & $23,5 \mathrm{~A}$ & $22,33 \mathrm{AB}$ \\
Diâmetro $(\mathrm{mm})$ & $38,59 \mathrm{~B}$ & $43,95 \mathrm{~A}$ & $38,20 \mathrm{~B}$ \\
Firmeza da Polpa $(\mathrm{N})$ & 98 & 93,8 & 86,2 \\
Luminosidade da Casca $(* \mathrm{~L})$ & 59,34 & 59,90 & 58,12 \\
Cromaticidade da Casca $(* \mathrm{C})$ & 40,24 & 40,02 & 41,58 \\
Ângulo hue (cor) & $115,99 \mathrm{~B}$ & $116,07 \mathrm{~B}$ & $117,81 \mathrm{~A}$ \\
\hline
\end{tabular}

Médias seguidas de mesma letra na linha não diferem estatisticamente, pelo teste de Tukey, a $5 \%$ de probabilidade.

TABELA 3 - Análise de variância para massa fresca (mf), comprimento (ct.), diâmetro (dm.), firmeza (fz.), cor da casca $\left({ }^{*} \mathrm{~L},{ }^{*} \mathrm{C}\right.$ e ${ }^{\circ}$ ), resistência ao despencamento ( $\left.\mathrm{rd}\right), \mathrm{pH}$, sólidos solúveis (ss) e acidez titulável (at) de 'Prata-Anã', 'BRS Platina' e 'Fhia-18'no estádio de maturação 6.

\begin{tabular}{lcccccccccccc}
\hline \multicolumn{1}{c}{ FV } & GL & Mf & ct & dm & fz & L & C & h & rd & pH & ss & at \\
\hline Genótipos & 2 & $853,9^{*}$ & $14,06^{*}$ & $0,9 \mathrm{~ns}$ & $8,77^{*}$ & $4,81^{*}$ & $123,7^{*}$ & $22,79^{*}$ & $9,28^{*}$ & $0,19^{*}$ & $13,4^{*}$ & $0,0002^{*}$ \\
Resíduo & 6 & 27,81 & 0,45 & 15,03 & 1,06 & 0,17 & 4,89 & 0,45 & 0,82 & 0,00006 & 0,027 & $0,20 \mathrm{E}^{-05}$ \\
\hline CV (\%) & & 3,83 & 3,2 & 9,9 & 8,9 & 0,57 & 4,4 & 0,7 & 13,5 & 0,18 & 0,68 & 3,03 \\
\hline
\end{tabular}

*, ns = significativo e não significativo a $5 \%$, respectivamente, pelo teste $\mathrm{F}$.

TABELA 4 - Caracterização pós-colheita de'Prata-Anã', 'BRS Platina'e 'Fhia-18'no estádio de maturação 6.

\begin{tabular}{lccc}
\hline \multirow{2}{*}{ Características } & \multicolumn{3}{c}{ Genótipos } \\
\cline { 2 - 4 } & Prata-Anã & BRS Platina & Fhia-18 \\
\hline Massa Fresca $(\mathrm{g})$ & $118,65 \mathrm{~B}$ & $143,92 \mathrm{~A}$ & $150,65 \mathrm{~A}$ \\
Comprimento $(\mathrm{cm})$ & $18,5 \mathrm{~B}$ & $22,23 \mathrm{~A}$ & $22,27 \mathrm{~A}$ \\
Diâmetro $(\mathrm{mm})$ & 38,41 & 39,42 & 39,37 \\
Resistência ao Despencamento $(\mathrm{N})$ & $5,01 \mathrm{~B}$ & $6,37 \mathrm{~A}$ & $6,98 \mathrm{~A}$ \\
Firmeza da Polpa $(\mathrm{N})$ & $11,43 \mathrm{AB}$ & $13,32 \mathrm{~A}$ & $9,91 \mathrm{~B}$ \\
pH & $4,71 \mathrm{~A}$ & $4,50 \mathrm{~B}$ & $4,2 \mathrm{C}$ \\
Sólidos Solúveis & $26,7 \mathrm{~A}$ & $23,18 \mathrm{~B}$ & $22,9 \mathrm{~B}$ \\
Acidez Titulável (mg ác. málico/100 g polpa fresca & $0,047 \mathrm{~B}$ & $0,038 \mathrm{C}$ & $0,055 \mathrm{~A}$ \\
Luminosidade da Casca $\left({ }^{*} \mathrm{~L}\right)$ & $71,86 \mathrm{~B}$ & $70,43 \mathrm{C}$ & $72,96 \mathrm{~A}$ \\
Cromaticidade da Casca $\left({ }^{*} \mathrm{C}\right)$ & $53,32 \mathrm{~A}$ & $42,89 \mathrm{~B}$ & $54,59 \mathrm{~A}$ \\
Ângulo hue (cor) & $92,71 \mathrm{~B}$ & $97,46 \mathrm{~A}$ & $92,67 \mathrm{~B}$ \\
\hline
\end{tabular}

Médias seguidas de mesma letra na linha não diferem estatisticamente, pelo teste de Tukey, a 5\% de probabilidade. 
TABELA 5 - Análise de variância dos dados da preferência para 'Prata-Anã', 'BRS Platina' e 'Fhia-18'.

\begin{tabular}{ccc}
\hline FV & GL & Preferência entre os genótipos \\
\hline Genótipos & 2 & \\
Resíduo & 126 & 21,14 \\
\hline CV $(\%)$ & &
\end{tabular}

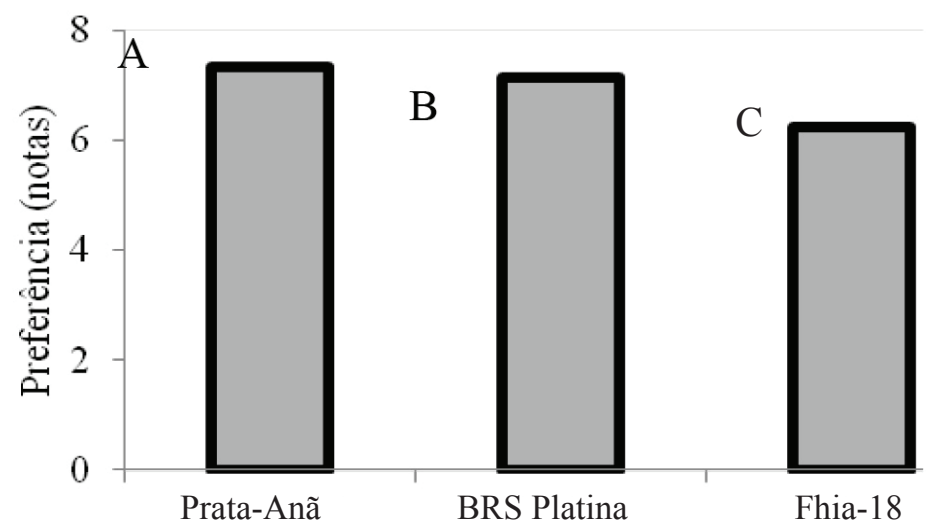

FIGURA 1 - Médias de preferência dos consumidores para 'Prata-Anã', 'BRS Platina' e 'Fhia-18', em penca. Letras iguais indicam não significância ( $\mathrm{p}>0,05$ pelo teste de Tukey). Avaliadas em escala hedônica estruturada variando de 1- Desgostei extremamente a 9 - Gostei extremamente.

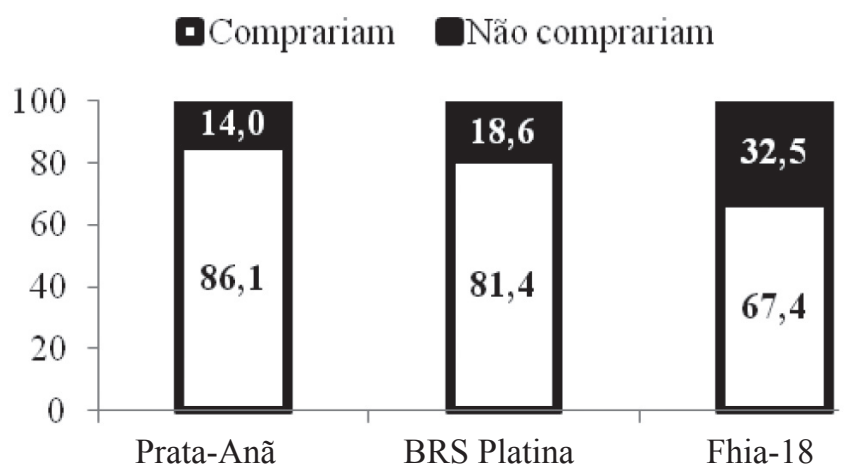

FIGURA 2 - Intenção de compra (\%) para 'Prata-Anã', 'BRS Platina’ e 'Fhia-18'. 

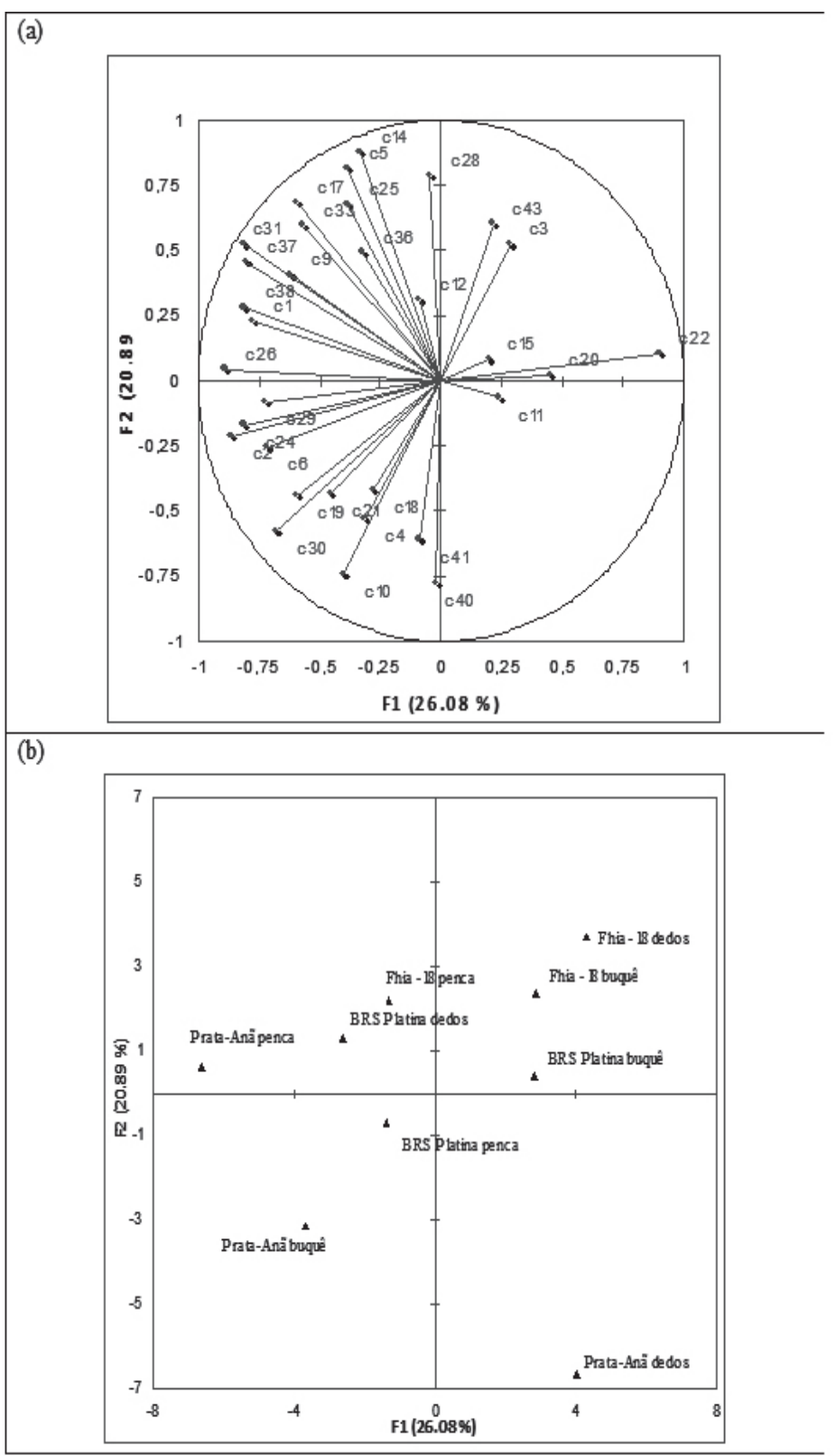

FIGURA 3 - Mapa Interno da Preferência, mostrando (a): a posição dos consumidores, e (b) a posição dos genótipos nas distintas formas de apresentação, considerando as dimensões 1 e 2. 

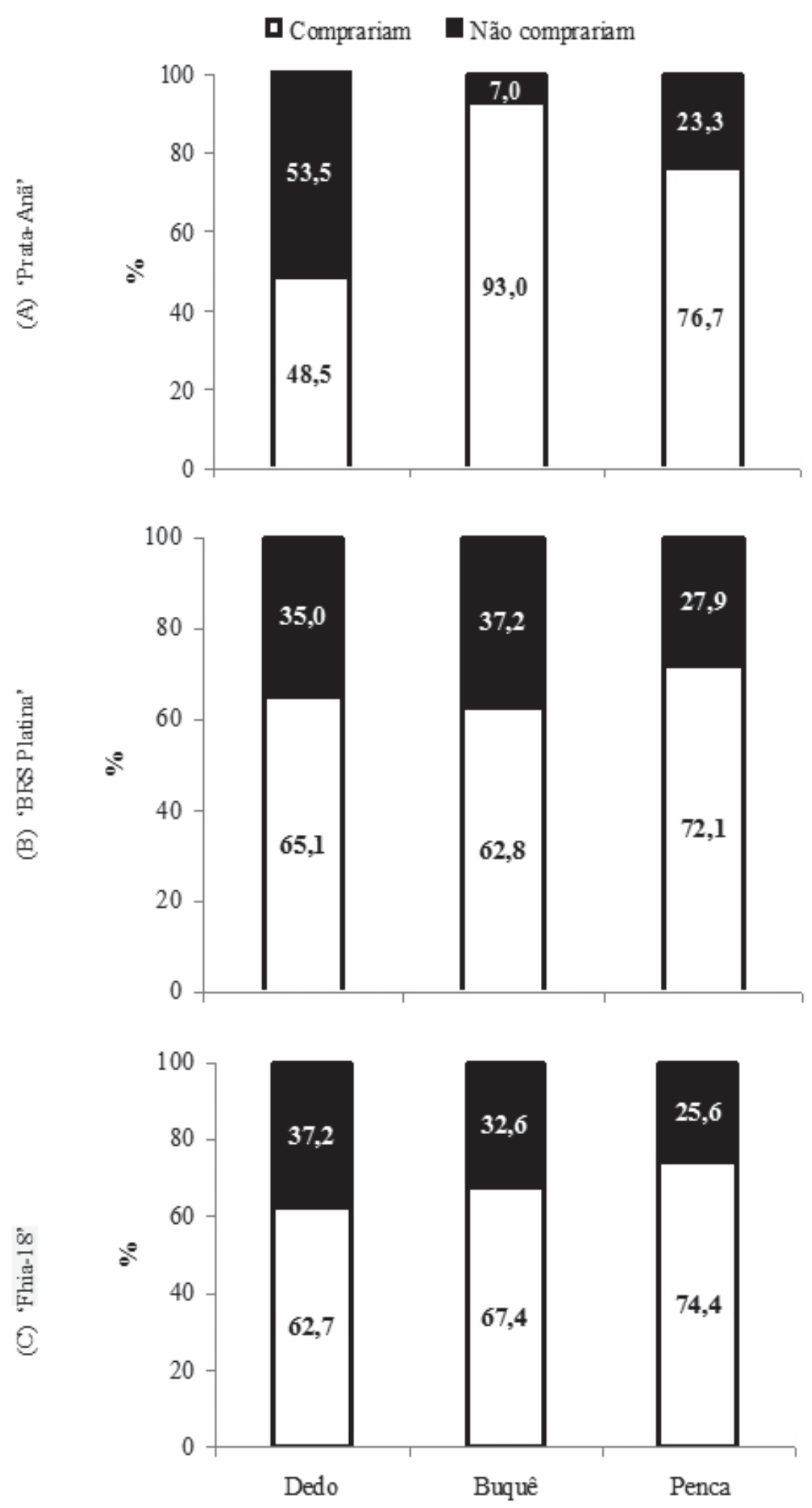

FIGURA 4 - Intenção de compra (\%) para 'Prata-Anã' (A), 'BRS Platina' (B) e 'Fhia-18' (C), apresentadas na forma de dedos, buquê ou penca. 


\section{CONCLUSÕES}

No ponto de colheita, o genótipo BRS Platina possui maior diâmetro e massa fresca, porém mesmo comprimento que 'Fhia-18'. Frutos de 'Fhia-18' têm a tonalidade da cor da casca mais intensa que a dos demais genótipos.

No estádio seis de maturação, 'BRS Platina' e 'Fhia-18' possuem a mesma massa, comprimento e resistência ao despencamento. Bananas `BRS Platina 'e 'Prata-Anã' têm a mesma firmeza. O genótipo 'Fhia-18' é o mais ácido e 'BRS Platina' tem menor acidez Bananas 'Prata-Anã' têm maior teor de sólidos solúveis, e 'BRS Platina' têm a tonalidade amarela da casca mais intensa que 'Prata-Anã' e 'Fhia-18'.

Os genótipos 'Prata-Anã' e 'BRS Platina' são preferidos e com maior intenção de compra pelos consumidores. A maioria dos consumidores compraria 'Prata-Anã' em buquê e 'BRS Platina e 'Fhia-18' em penca.

\section{AGRADECIMENTOS}

À Fapemig, pelo auxílio financeiro e bolsas de pesquisa para a execução deste trabalho.

\section{REFERENCIAS}

ALLEN, R. G.; PEREIRA, L. S.; RAES, D.; SMITH, M. Crop evapotranspiration: guidelines for computing crop water requirements. Rome: FAO, 1998. 300p.

ANTUNES, F. Z. Caracterização climática do Estado de Minas Gerais. Informe Agropecuário, Belo Horizonte, v.12, n.138, p.9-13, 1986.

AZZOLINI, M.; JACOMINO, A.P.; BRON, I.U. Índices para avaliar qualidade pós-colheita de goiabas em diferentes estádios de maturação. Pesquisa Agropecuária Brasileira, Brasília, v.39, n.2, p.139-145, 2004.

CASTRICINI, A.; COELHO, E. F.; OLIVEIRA, P. M. de; RODRIGUES, M. G. V.; SANTOS, M. G. dos. Qualidade de bananas de diferentes genótipos produzidas no semiárido mineiro. In: CONGRESSO BRASILEIRO DE FRUTICULTURA, 22., 2012, Bento Gonçalves. Anais ... Bento Gonçalves: SBF, 2012. 1 CD-ROM.
CEAGESP. Programa Brasileiro para a Modernização da Horticultura \& Produção Integrada de Frutas. Normas de classificação de banana. São Paulo, 2006. (Documentos, 29). Disponível em: http://www. hortibrasil.org.br/jnw/images/stories/folders/banana. pdf. Acesso em: 05 ago. 2013.

CORDEIRO, Z. J. M. ; VIEIRA, J. F. ; MATOS, A. P. de ; SILVA, S. de O. e . Resistência de genótipos tetraploides de bananeira à Sigatoka-amarela. In: REUNIÃO INTERNACIONAL ACORBAT, 17., 2006, Santa Catarina. Anais ... Santa Catarina: Epagri, 2006. p. 433-436.

COSTA, F. da S.; COELHO, E. F.; BORGES, A. L.; PAMPONET, A. J. M.; SILVA, A. dos A. S. M. da; AZEVEDO, N. F. de. Crescimento, produção e acúmulo de potássio em bananeira 'Galil 18' sob irrigação e fertilização potássica. Pesquisa Agropecuária Brasileira, Brasília, v.47, n.3, p. 409-416, 2012.

DONATO, S. L. R.; OLIVEIRA e SILVA, S. de.; LUCCA FILHO, O. A.; LIMA, M. B.; DOMINGUES, H.; ALVES, J. da S. Comportamento de variedades e híbridos de bananeira (Musa spp.), em dois ciclos de produção no sudoeste da Bahia. Comunicação Científica. Revista Brasileira de Fruticultura, Jaboticabal, v. 28, n. 1, p. 139-144, 2006.

GOMES, M. da C.; VIANA, A. P.; OLIVEIRA, J. G. de; PEREIRA, M. G.; GONÇALVES, G. M.; FERREIRA, C. F. Avaliação de germoplasma elite de bananeira. Revista Ceres, Viçosa, v.54, n.312, p. 18-190, 2007.

GREENHOFF K.; MacFIE, H.J.H. Preference mapping in practice. In: MAcFIE, H.J.H.; THOMSON, D.M.H. (Ed.). Measurement of food preferences. Glasgow: Blackie Academic and Professional, 1994. p. 137-165.

IBGE. Produção agrícola municipal. Disponível em: $<$ http://www.sidra.ibge.gov.br/ =bda/agric/default. asp? $\mathrm{z}=\mathrm{t} \& \mathrm{o}=11 \& \mathrm{i}=\mathrm{P}>$. Acesso em: 12 mar. 2013.

IBRAF - Instituto Brasileiro de Frutas. Panorama da cadeia produtiva das frutas em 2012 e projeção para 2013. Brasília: IBRAF, 2013. 133 p.

INSTITUTO ADOLFO LUTZ. Normas analíticas do Instituto Adolfo Lutz. Métodos químicos e físicos de análise de alimentos. 3. ed. São Paulo, 1987. 
JESUS, S. C. de; FOLEGATTI, M. I. da S.; MATSUURA, F. C. A. U.; CARDOSO, R. L. Caracterização física e química de frutos de diferentes genótipos de bananeira. Bragantia, Campinas, v.63, n.3, p.315-323, 2004.

LOESECKE, H.W.V. Bananas: chemistry, physiology, and technology. New York: Chapman and Hall, 1950. 189p.

MEILGARD, M.; CIVILlE, G.V.; CARR, B.T. Sensory evolution techniques. Gainsville: CRC Press, 1988.

MORAIS, P. L. D. de.; FILGUEIRAS, H. A. C.; PINHO, J. L. N. de; ALVES, R. E. Ponto de colheita ideal de mangas 'Tommy Atkins' destinadas ao mercado europeu. Revista Brasileira de Fruticultura, Jaboticabal, v.24, n.3, p.671-675. 2002.

NEW, S.; MARRIOTT, J. Factores affecting the development of 'finger drop' in bananas after ripening. Journal of Food Technology, Oxford, v. 18, n. 2, p. 241-250, 1983.

NOMURA, E. S.; DAMATTO Jr., E. R.; FUZITANI, E. J.; AMORIM, E. P.; SILVA, S. de O. e. Avaliação agronômica de genótipos de bananeiras em condições subtropicais, Vale do Ribeira, São Paulo - Brasil. Revista Brasileira de Fruticultura, Jaboticabal, v.35, n.1, p. 112-122, 2013.

OLIVEIRA, C. G. de; PINHEIRO, J. M. da S.; DONATO, S. L. R.; SANCHÊS, C. L. G.; VILA, M. T. R.; MOURA, M. F. de; PIMENTEL, R. M. de A.; RESENDE, J. C. F. de. Efeito da temperatura de armazenamento sobre a firmeza e o despencamento dos genótipos de banana 'Prata-Anã' e PA42-44. In: SIMPÓSIO BRASILEIRO SOBRE BANANICUlTURA, 7., 2010a, Registro. Anais ... Registro: SBF, 2010. p.80-83.

OLIVEIRA, C. G. de; SANCHÊS, C. L. G.; PINHEIRO, J. M. da S.; MIZOBUTSI, G. P.; DONATO, S. L. R.; DAMASCENO, J. E. A. Caracterização físico-química e sensorial de frutos de banana 'Prata-Anã' e PA42-44. In: SIMPÓSIO BRASILEIRO SOBRE BANANICULTURA, 7., 2010b, Registro. Anais ... Registro: SBF, 2010. p.52-56.

OLIVEIRA, T. K. de; LESSA, L. S.; SILVA, S. de O. e; OLIVEIRA, J. P. de. Características agronômicas de genótipos de bananeira em três ciclos de produção em Rio Branco-AC. Pesquisa Agropecuária Brasileira, Brasília, v.43, n.8, p. 1003-1010, 2008.
PEREIRA, M. C. T.; SALOMÃO, L. C. S.; SILVA, S. de O. e. Suscetibilidade à queda natural e caracterização dos frutos de diversos genótipos de bananeiras. Revista Brasileira de Fruticultura, Jaboticabal, v.26, n.3, p. 499-502, 2004.

PIMENTEL, R. M. de A.; GUIMARAES, F. N.; SANTOS, V. M.; RESENDE, J. C. F. de. Qualidade pós-colheita dos genótipos de banana PA42-44 e Prata-Anã cultivados no norte de Minas Gerais. Revista Brasileira de Fruticultura, Jaboticabal, v.32, n.22, p.407-413, 2010.

RODRIGUES, M. G. V.; DIAS, M. S. C.; PACHECO, D. D. (Coord.). Bananicultura irrigada: inovações tecnológicas. Belo Horizonte: Epamig, 2008. v.1., $120 \mathrm{p}$.

SAEG. Sistema para análises estatísticas, Versão 9. Viçosa: Fundação Arthur Bernardes, 2007.

SANTOS, C. M. S.; VILAS BOAS, E. V. de B.; BOTREL, N.; PINHEIRO, A. C. M. Influência da atmosfera controlada sobre a vida pós-colheita e qualidade de banana 'Prata Ana'. Ciência e Agrotecnologia, Lavras, v.30, n.2, p. 317-322, 2006.

SILVA, C. de S.; LIMA, L. C.; SANTOS, H. S.; CAMILI, E. C.; VIEIRA, C. R. Y. I.; MARTIN, C. da S.; VIEITES, R. L.Amadurecimento da banana-prata climatizada em diferentes dias após a colheita. Ciência e Agrotecnologia, Lavras, v.30, n.1, p. 103-111, 2006.

SILVA, M. J. R. da; ANJOS, J. M. C. dos; JESUS, P. R. R. de; SANTOS, G. S. dos; LIMA, F. B. F.; RIBEIRO, V. G. Produção e caracterização da bananeira 'Prata-Anã' (AAB) em dois ciclos de produção (Juazeiro, Bahia). Revista Ceres, Viçosa, v. 60, n. 1, p.122-126, 2013.

SILVA, S. de O. e; FLORES, J.C.O.; LIMA NETO, F.P. Avaliação de cultivares e híbridos de bananeira em quatro ciclos de produção. Pesquisa Agropecuária Brasileira, Brasília, v.37, n. 11, p.1.567-1.574, 2002.

SILVA, T. N.; CALASANS, T. N.; MARTINS, C. R.; LÉDO, A. da S.; AMORIM, E. P.; LÉDO, C. A. da S. Caracteres químicos em pós-colheita de bananas de diferentes genótipos cultivados no Estado de Sergipe. In: CONGRESSO BRASILEIRO DE FRUTICULTURA, 22., 2012, Bento Gonçalves. Anais ... Bento Gonçalves: SBF, 2012. 1 CD-ROM.

STONE, H.; SIDEL, J.L. Sensory evaluation practices. Orlando: Academic Press, 1995. 311 p. 